\title{
Modeling and Simulation of Photofabrication Processes Using Unsaturated Polyester Resins
}

\author{
João Manuel Matias, ${ }^{1,2}$ Paulo Jorge Bartolo, ${ }^{1}$ António Vilela Pontes ${ }^{2}$ \\ ${ }^{1}$ Centre for Rapid and Sustainable Product Development, Mechanical Engineering Department, \\ School of Technology and Management, Polytechnic Institute of Leiria, Leiria, Portugal \\ ${ }^{2}$ Institute of Polymers and Composites, Polymer Engineering Department, University of Minho, Guimarães, Portugal
}

Received 7 July 2008; accepted 5 February 2009

DOI 10.1002/app.30405

Published online 17 August 2009 in Wiley InterScience (www.interscience.wiley.com).

\begin{abstract}
Several kinetic models have been proposed to simulate thermosetting cure reactions. The most complex models, based on a mechanistic approach of cure reactions, are developed based on the concepts of free radical polymerization and the mechanism of reactions with diffusion. However, mechanistic models are usually quite impractical for engineering purposes because of the difficulty in obtaining the model parameters. An alternative to these mechanistic models are the phenomenological models, formulated in terms of the degree of cure and much easier to apply. Phenomenological models have been largely used to study thermal-initiated cure reactions, although only few works
\end{abstract}

used them to model the kinetics of ultraviolet-initiated cure reaction. This work proposes a photo-thermal-kinetic model to study the behavior of unsaturated polyester resins during ultraviolet-initiated cure reactions. The model considers samples with different amounts of initiator concentration and cure reactions performed under different ultraviolet light intensities. The model has been numerically solved using the finite element technique. (c) 2009 Wiley Periodicals, Inc. J Appl Polym Sci 114: 3673-3685, 2009

Key words: computer modeling; curing of polymers; photopolymerization; polyesters

\section{INTRODUCTION}

Photoinitiated curing reactions of thermosetting resins are polymerization processes characterized by chemical crosslinking reactions, which create an infusible, insoluble, and highly crosslinked 3D network. ${ }^{1,2}$ Cure reaction of thermosetting resins differs from thermoplastic (linear polymer) polymerizations, where the chains grow in a single direction. The irradiation of the initial samples initiates an exothermic reaction, characterized by two main events: ${ }^{3-6}$

- gelation, i.e., liquid-to-rubber transition, and

- vitrification, i.e., liquid or rubber-to-glass transition.

Gelation is a nonreversible event corresponding to the incipient formation of an infinite molecular network, which is associated with a dramatic increase of viscosity. ${ }^{3}$ At this point, the system will no longer flow and two phases coexist: a gel phase and a sol phase. ${ }^{7}$ The gel phase is the gelled part, insoluble in nondegrading solvents, whereas the sol phase,

Correspondence to: P. J. Bartolo (pbartolo@estg.ipleiria.pt). Contract grant sponsor: Portuguese Foundation for Science and Technology; contract grant number: POCTI/ EME/58405/2004.

Journal of Applied Polymer Science, Vol. 114,3673-3685 (2009) (c) 2009 Wiley Periodicals, Inc. which remains soluble, can be extracted with solvents.

Vitrification corresponds to the formation of a glassy solid material due to an increase in both the crosslinking density and the molecular weight of the polymer being cured, and usually follows gelation., 3 Afterward, the rate of reaction will undergo a significant decrease, and the reaction becomes very slow as it is controlled by the diffusion of the reactive species. ${ }^{9,10}$ In this way, vitrification represents the change, from a reaction that is predominantly kinetically controlled to a diffusion-controlled reaction. . $^{3,10}$ The diffusion-controlled effect, apart from causing a slow down of the conversion reaction, determines the final degree of conversion obtained.

This article presents an integrated photo-thermalkinetic model to study photofabrication processes with unsaturated polyester resins. This model describes both irradiation mechanisms and the exothermic characteristics of the curing reaction, besides being able to describe the major events (vitrification, diffusion limitations, incomplete conversion, etc.) occurring during the chemical process of solidification.

\section{CURING OF UNSATURATED POLYESTER RESINS}

The curing reaction of unsaturated polyester (UP) resins with styrene is a free radical polymerization 
and comprises three major reactions: styrene-polyester vinylene, styrene-styrene, and polyester vinylene-polyester vinylene. ${ }^{11-16}$ The styrene homopolymerization forms a soluble polystyrene segment, which does not contribute to the network formation. ${ }^{13,14}$

Studies on copolymerization of styrene and diethyl fumarate suggest that homopolymerization of styrene monomer is significant in relation to the copolymerization between styrene and polyester vinylene. ${ }^{17}$ Therefore, the styrene monomer in UP resins is always present in stoichiometric excess when compared with the polyester vinylenes. ${ }^{18}$ The styrene homopolymerization, however, proceeds much less readily than the styrene-polyester vinyl copolymerization. ${ }^{14,18}$

The polyester vinylene homopolymerization is much more difficult to achieve than the other reactions because of the relative immobility of the long polyester chains. ${ }^{12-14,18}$ Nevertheless, if the concentration of polyester vinylenes becomes much higher than the concentration of styrene monomer, at a local site, the polyester vinylene homopolymerization may be more favorable than the copolymerization between styrene and polyester at that location. ${ }^{12,14}$ This was indicated by Cook and Delatycki ${ }^{19}$ whose results showed that, in addition to styrene fumarate copolymerization, a fumarate-fumarate crosslinking reaction occurred when the styrene monomer concentration was low. Yang et al. ${ }^{20}$ studied the cure kinetics of UP resins and also found that at low conversions, the polyester reaction was more favorable than the styrene reaction because of the intramolecular cyclization of polyester chains, whereas at high conversions, the styrene reaction became predominant.

The UP resin system can be described as a collection of coiled polyester chains swollen in the styrene monomer. ${ }^{13,14}$ The size of these coils depends on several factors such as the polyester molecular chain length, the chain stiffness, the compatibility of UP molecules with the styrene monomer, and the concentration of the polyester chain. ${ }^{14} \mathrm{~A}$ chemical reaction may occur inside, outside, and at the surface of the coils (Fig. 1). ${ }^{13,14}$

Before the start of the curing reaction, the resin system usually contains UP molecules, styrene monomers, inhibitors, and initiators. ${ }^{21-23}$ Under irradiation, the initiator splits into free radicals. At the very beginning of the reaction, most of the free radicals are consumed by the inhibitor, which acts as a retarder of the polymerization, and reacts with the radicals until it is exhausted. ${ }^{21-23}$ Very little polymerization occurs at this stage, which is called the inhibition or induction stage. ${ }^{23}$ When the inhibitor concentration becomes low, the vinyl bonds (i.e., $\mathrm{C}=\mathrm{C}$ bonds) on the polyester and styrene molecules are able to compete for the initiator radicals. ${ }^{21}$ After

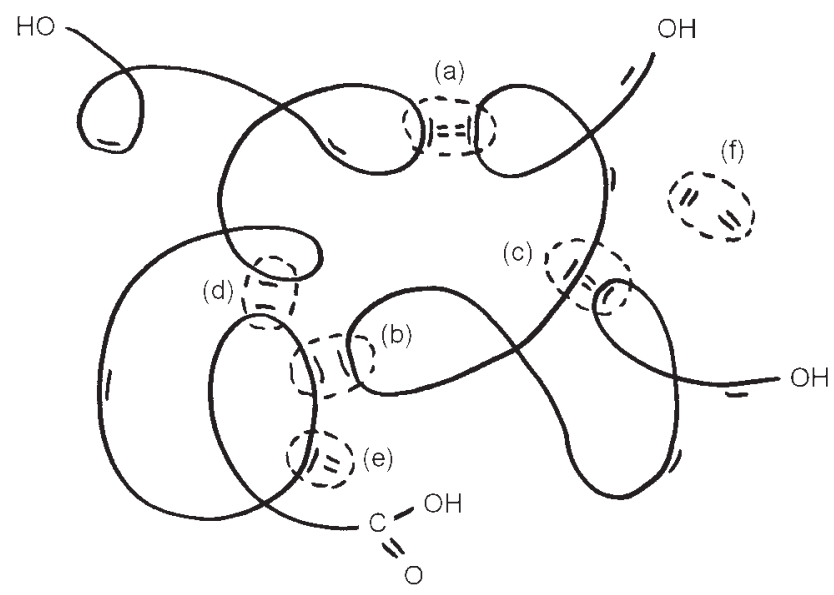

Figure 1 Possible reactions in the styrene-UP copolymerization. These reactions can be divided into four mechanisms: intermolecular crosslinking (Reactions a and b), intramolecular cyclization (Reactions $\mathrm{c}$ and $\mathrm{d}$ ), branching growth (Reaction e), and styrene homopolymerization (Reaction f).

this stage, the free radicals will start the reaction by linking adjacent UP molecules and form long-chain molecules through the connection of styrene monomers, by both inter and intramolecular reactions. ${ }^{24}$

These long-chain molecules tend to form spherical structures, called microgels or primary polymers, because of the intramolecular crosslinking reactions. ${ }^{13,14}$ Dusek $^{25}$ described these microgels as high cyclization and crosslinking density structures. Moreover, because of the high crosslinking of the microgels, many pendant vinyls are buried inside these structures. ${ }^{13}$ This phenomenon, called the "molecular shielding" effect, causes the diffusion-controlled termination reaction effect, which means that termination among the polymer radicals may not be an important factor. ${ }^{23}$

As the reaction proceeds, interparticle reactions among microgels will occur with the formation of larger clusters. ${ }^{13,14}$ These reactions will occur through polyester vinyl bonds at, or near, the surface core of the microgels, with styrene monomers serving as chain extenders. Finally, more and more domains are formed and connected, forming a cocontinuous structure.

\section{MODELING}

The curing process is an exothermic reaction whose heat generation rate is important to be evaluated. The heat generation rate is described by the following equation:

$$
\dot{Q}=\Delta H_{\text {TOTAL }} \times R_{P}
$$

where $\Delta H_{\text {TOTAL }}$ is the total enthalpy variation and $R_{P}$ is the reaction rate. 
Three different approaches were developed to model the reaction rate:

- Energetic models,

- Mechanistic and semimechanistic models, and

- Phenomenological models.

\section{Energetic models}

The energetic models were proposed by Yamaguchi and Nakamoto ${ }^{26}$ assuming that the cure process begins only when a critical value of energy is reached, which depends on the material being used. These models are based on a direct relation between the radiation intensity, radiation profile, and energy, developed to simulate both direct irradiation and mask irradiation processes.

\section{Mechanistic and semimechanistic models}

Mechanistic models are based on both the concept of free radical polymerization and the mechanism of reactions with diffusion. ${ }^{27-29}$ This approach requires several assumptions and approximations to simplify the complexity of the curing reaction. The rate constants in the free radical polymerization reactions have been modified by introducing the molecular parameters of free volume and glass transition temperature incorporating the effect of diffusion. In this way, these models have pointed out that the model equations often include many parameters that must be determined using numerical optimization schemes.

Photocuring processes are chain reactions characterized by three main steps: photoinitiation, propagation, and termination. The photoinitiation mechanism occurs when photons of a laser radiation source collide with a photoinitiator molecule, generating the formation of reactive species. The addition of the reactive species to monomers, followed by successive additions forming a growing polymer chain comprises the propagation step. This propagation will continue until some reaction occurs, which terminates it.

A typical radical polymerization mechanisms can be described as follows:

$$
\begin{aligned}
& \left.\begin{array}{c}
P I \stackrel{h v}{\longrightarrow} R^{\bullet} \\
M+R^{\bullet} \stackrel{k_{i}}{\longrightarrow} P_{1}^{\bullet}
\end{array}\right\} \quad \text { initiation } \\
& P_{n}^{\bullet}+M \stackrel{k_{p}}{\longrightarrow} P_{n+1}^{\bullet} \quad \text { propagation } \\
& P_{n}^{\bullet}+P_{m}^{\bullet} \stackrel{k_{t c}}{\longrightarrow} M_{n+m} \quad \text { termination by combination } \\
& P_{n}^{\bullet}+P_{m}^{\bullet} \stackrel{k_{t d}}{\longrightarrow} M_{n}+M_{m} \quad \text { termination by } \\
& \text { disproportionality }
\end{aligned}
$$

where $P I$ and $M$ are the photoinitiator and the monomer, respectively, $R^{\bullet}$ is the primary radical, and $P_{n}^{\bullet}$ is the polymeric radical with a chain size of $n$ units of monomer.

The rate of monomer depletion, called the rate of polymerization, is given by the following equation:

$$
-\frac{d[M]}{d t}=R_{P}=k_{P}[M]\left[P^{\bullet}\right]=k_{P}[M]_{0}(1-\alpha)\left[P^{\bullet}\right]
$$

The total concentration of polymeric radicals $\left[P^{\bullet}\right]$ is given by:

$$
\frac{d\left[P^{\bullet}\right]}{d t}=R_{i}-R_{t}=\phi_{i} I_{\mathrm{a}}-k_{t}\left[P^{\bullet}\right]^{b}
$$

where $\phi_{i}$ is the quantum efficiency of the initiation and $I_{a}$ is the light intensity. The exponent $b$ is equal to 2 for bimolecular termination processes and is equal to 1 either for unimolecular termination or radical trapping mechanisms. ${ }^{23}$

\section{Phenomenological models}

Phenomenological models were developed assuming that only one reaction can represent the whole curing process and are given by the following equation:

$$
\frac{d \alpha}{d t}=k_{c}(T) f(\alpha)
$$

where $d \alpha / d t$ is the reaction rate, $f(\alpha)$ is a function of conversion, and $k_{c}(T)$, the chemical-controlled rate constant, is a function of temperature.

The simplest and most common analytical form of $f(\alpha)$ is given by:

$$
f(\alpha)=(1-\alpha)^{n}
$$

where $n$ is a constant that corresponds to the reaction order. By substituting eq. (6) in eq. (5), the following equation is obtained:

$$
\frac{d \alpha}{d t}=k_{c}(T) \cdot(1-\alpha)^{n}
$$

which corresponds to the so-called $n$th order kinetic model.

The rate constant is supposed to observe an Arrhenius law, so it can be expressed by:

$$
k_{c}(T)=k_{0} \exp \left(\frac{-E}{R(\Delta+T)}\right)
$$

where $k_{0}$ is a preexponential factor or frequency factor, $E$ is the activation energy, $R$ is the gas constant, $T$ is the temperature in ${ }^{\circ} \mathrm{C}$, and $T+\Delta$ is the absolute temperature $\left(\Delta=273^{\circ} \mathrm{C}\right)$, indicated hereafter as $T_{\mathrm{abs}}$. 
Considering the rate constant expression, eq. (7) is given by:

$$
\frac{d \alpha}{d t}=k_{0} \exp \left(-\frac{E}{R T_{\mathrm{abs}}}\right) \cdot(1-\alpha)^{n}
$$

For an isothermal reaction, the $n$th order kinetic by expression given by eq. (9) predicts a maximum of the reaction rate, at time $t=0$. However, if an isothermal process is characterized by a thermogram showing a maximum value of the reaction rate at any point, rather than the reaction starting point, the $n$th order kinetic model cannot be applied. In these cases, the $n$th order models are usually replaced by the so-called autocatalytic models, which were initially proposed by Kamal and Sourour ${ }^{30}$ :

$$
\frac{d \alpha}{d t}=\left(k_{c 1}(T)+k_{c 2}(T) \alpha^{m}\right)(1-\alpha)^{n}
$$

where $k_{c 1}(T)$ and $k_{c 2}(T)$ are rate constants expressed by eq. (8), and $m$ and $n$ are constants whose sum is the overall reaction order. The order of the reaction, according to its definition, indicates the number of atoms, molecules, or reactive groups whose concentration determines the reaction rate.

The Kamal model was modified by Bártolo ${ }^{23}$ for stereolithographic processes, incorporating the effects of radiation over the curing process. In Bártolo's model, the kinetics parameters are defined as functions of temperature, resin composition, light intensity, and fractional conversion. 23,28,29 Diffusioncontrolled effects characterizing the vitrification phenomena are also considered.

\section{PHOTO-THERMAL-KINETIC MODEL FOR CURING SIMULATION}

The proposed model is based on the understanding of the fundamental physical and chemical phenomena governing the behavior of a thermosetting material in photoinitiated curing applications. A number of assumptions were made for its development:

- a simplified isotropic/anisotropic material, with density $\rho$, specific heat $C$, thermal conductivities $k_{r}$ and $k_{z}$, and total heat release $H$;

- a well mixed and homogeneous polymeric system;

- any optical scattering effects and the flow of material due to convection or diffusion are both considered negligible;

- the internal heat generation is only due to the heat of polymerization; and

- the absorption of UV radiation is defined by the Beer-Lambert law.
According to the model, the temperature field in the exposed region is described by the two-dimensional heat conduction equation in cylindrical coordinates $(r, z)$ :

$$
\begin{aligned}
& \rho C \frac{\partial T}{\partial t}=\frac{1}{r} \frac{\partial}{\partial r}\left(r k_{r} \frac{\partial T}{\partial r}\right)+\frac{\partial}{\partial z}\left(k_{z} \frac{\partial T}{\partial z}\right)+\rho H \frac{d \alpha}{d t} \\
& \text { transient }=\quad \text { conduction } \quad+\text { generation }
\end{aligned}
$$

where $T$ is the temperature, $t$ is the time, and $d \alpha / d t$ corresponds to the kinetic model.

The solution of the eq. (11) requires both knowledge of the initial temperature, $T_{i}$, and the initial value of the fractional conversion, $\alpha_{i}$, in the domain $\Omega$ being studied:

$$
\begin{aligned}
& T(v, 0)=T_{i} \\
& \alpha(v, 0)=\alpha_{i}
\end{aligned}
$$

where $v$ represents a generic point in the space. Additionally, the solution of eq. (11) must satisfy the following boundary conditions, as shown in Figure 2:

- Specified temperature

$$
T_{s}=T(v, t) \text { at } \Gamma_{1}
$$

- Specified light intensity

$$
k_{n} \frac{\partial T}{\partial n}-I(v, t)=0 \text { at } \Gamma_{2}
$$

- Convection boundary condition

$$
k_{n} \frac{\partial T}{\partial n}+h\left(T(v, t)-T_{\infty}\right)=0 \text { at } \Gamma_{3}
$$

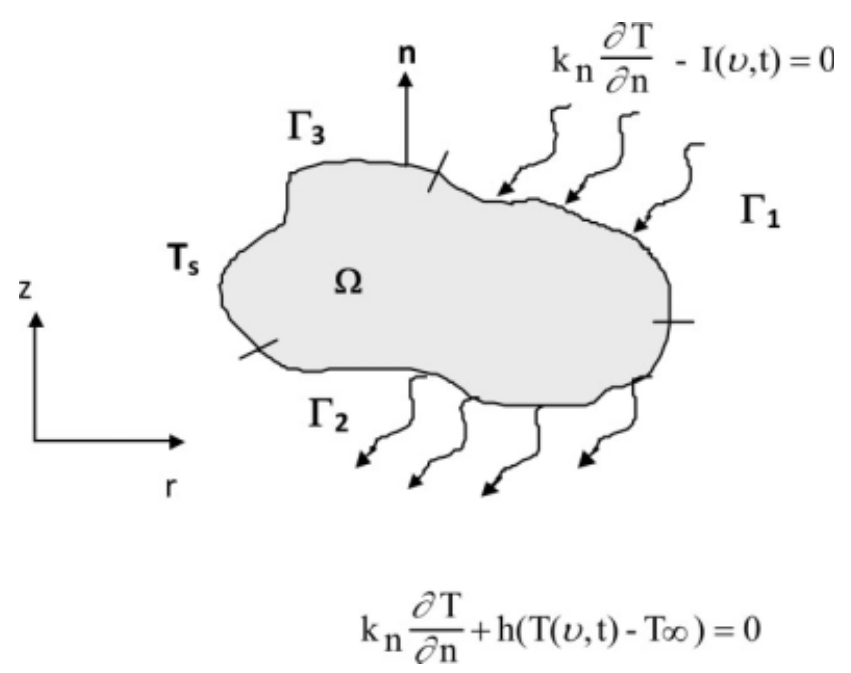

Figure 2 Boundary conditions. 


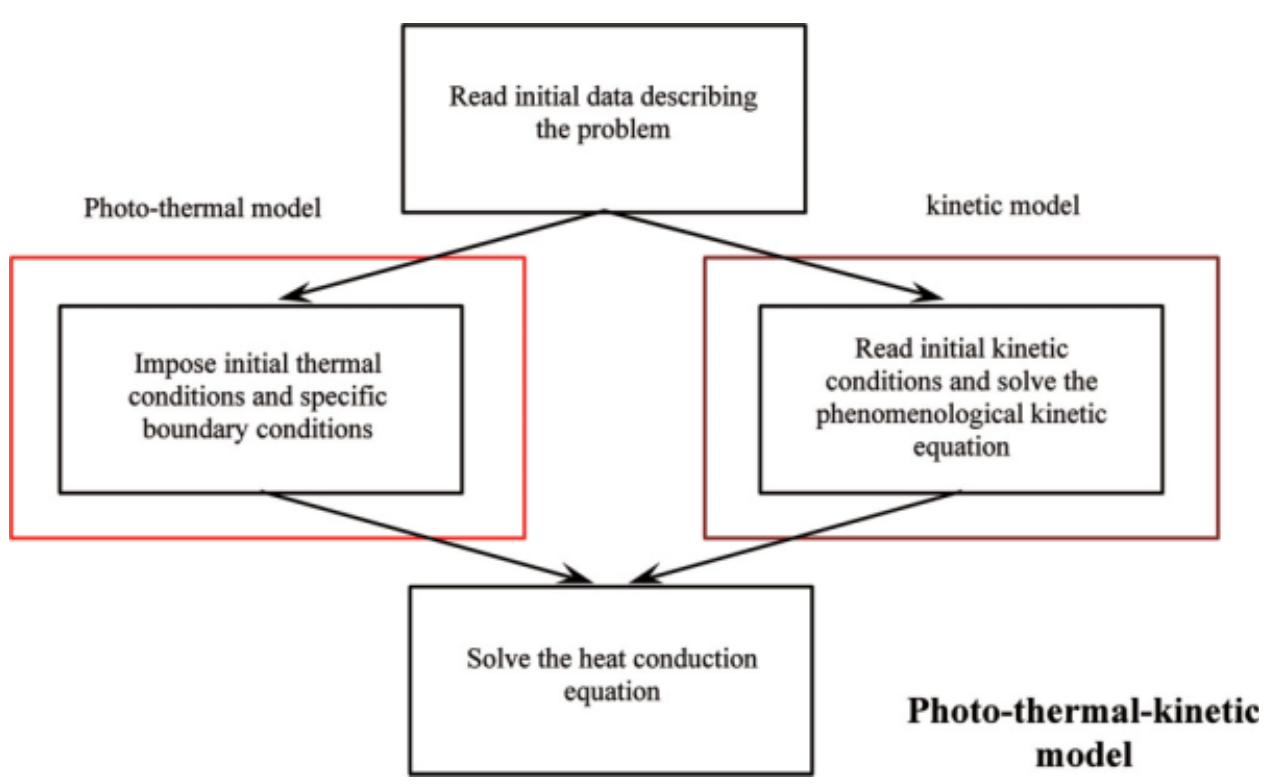

Figure 3 Flow information in the photo-thermal-kinetic model. [Color figure can be viewed in the online issue, which is available at www.interscience.wiley.com.]

where $T_{s}$ is the specified temperature, $I$ is the light intensity, $\partial T / \partial n$ is the derivative of temperature in the direction normal to the surface, $h$ is the coefficient of heat transfer, and $T_{\infty}$ is the temperature of the surrounding space. As a final remark, it is worth noting that the term $k_{n} \partial T / \partial n$ is given by:

$$
k_{n} \frac{\partial T}{\partial n}=k_{r} \frac{\partial T}{\partial r} \cos \left(n_{r}\right)+k_{z} \frac{\partial T}{\partial z} \cos \left(n_{z}\right)
$$

Light intensity values at the resin surface $I_{s}$ are defined by assuming a Gaussian intensity distribution as follows:

$$
I_{s}(v, t)=I_{0} \exp \left[-2\left(\frac{s(\mathrm{v}, t)}{w_{0}}\right)^{2}\right]
$$

with $I_{0}$ being the peak light intensity, $s(v, t)$ representing the position in time of a point under irradiation, and $w_{0}$ corresponding to the beam radius. The decrease in light intensity with depth is assumed to obey the Beer-Lambert law according to the following equation:

$$
I_{d}(v, t)=I_{s}(v, t) \exp [-\varepsilon[\beta] y]
$$

where $I_{d}$ represents the variation of the light intensity along the thickness of the resin layer, $\varepsilon$ is the absorptivity of the initiator, $[\beta]$ is the initiator concentration, and $y$ represents the penetration depth. For irradiation problems through masks, Fresnel's diffraction theory is applied to evaluate the effect of diffraction.
The kinetic model considered, representing a more realistic approach to describe the major phenomena (vitrification, diffusion limitations, incomplete conversion, radical trapping, etc.) occurring during photoinitiated curing reactions, is represented by the following equation: ${ }^{21}$

$$
\frac{d \alpha}{d t}=\frac{1}{1+\exp \left[\xi\left(\alpha-\alpha_{d}\right)\right]} \varphi I^{p} \exp \left(\frac{-E}{R T_{\mathrm{abs}}}\right)[\beta]^{q} \alpha^{m}(1-\alpha)^{n}
$$

where $\xi$ is the diffusion constant, $\alpha_{d}$ is the critical value of the fractional conversion corresponding to the onset of diffusion-controlled effects over the curing reaction, $\varphi$ is the preexponential factor of the rate constant, $I$ is the light intensity, $E$ is the activation energy, $R$ is the gas constant, $T_{a b s}$ is the absolute temperature, $p$ and $q$ are constants, and the exponents $m$ and $n$ represent the reaction orders, with the sum $(m+n)$ being the overall reaction order. The kinetic parameters, $\xi, \alpha_{d}, m, n$, and $E$, are not constants for this equation. In the absence of diffusion-controlled effects, the kinetic equation becomes

$$
\frac{d \alpha}{d t}=\varphi I^{p} \exp \left(\frac{-E}{R T_{a b s}}\right)[\beta]^{q} \alpha^{m}(1-\alpha)^{n}
$$

The kinetic model was experimentally validated for different polymeric systems (radicalar, cationic, and hybrid systems). ${ }^{23,31}$ Figure 3 briefly describes the flow of information necessary for the implementation of the photo-thermal-kinetic model. 


\section{COMPUTER IMPLEMENTATION}

The photo-thermal-kinetic model is solved using the finite element method (FEM), with linear rectangular elements and an appropriate time marching scheme as described later. Fractional conversions are evaluated by integrating (with respect to time) the rate of gel formation equation using the fourth-order fixed step-size Runge-Kutta technique.

The basic concept in FEM is the discretization of a general domain (continuum domain) into a finite number of subdomains, called elements. These elements are connected to each other by points called nodes, forming a grid of cells named as finite element mesh. The parameters assigned to each element or nodal variable are called degrees of freedom of the element. In a continuum domain, a field variable has an infinite number of unknowns because it is a function of each generic point in the domain. The finite element discretization will reduce the problem to one of a finite number of unknowns, with the behavior of the field variable within an element being represented through approximating functions called shape or interpolation functions. Through the FEM, the governing equations, usually in differential or integral form, are transformed into a set of algebraic equations, which are easier to manipulate. The solution of these equations gives the approximate behavior of the continuum medium.

The numerical solution of eq. (10), subjected to the initial conditions, eqs. (12) and (13), and to boundary conditions, eqs. (14)-(16), involves two stages of approximation:

- spatial approximation using the Galerkin method and

- temporal approximation using the Crank-Nicolson method.

\section{Spatial discretization}

The discretization of eq. (11) in space is accomplished by the discretization of the generic domain $\Omega$ into an appropriate collection of finite elements $\Omega e_{i}$ connected at nodes:

$$
\Omega=\sum_{i=1}^{k} \Omega e_{i}
$$

with $k$ being the number of elements and $\Omega e$ representing each element domain.

The element shape functions $N_{i}$ are used to interpolate the temperature ${ }^{32}$ :

$$
T(v, t)=\sum_{i=1}^{j} N_{i}(v) T_{i}(t)
$$

where $j$ represents the number of nodes of the considered element and $T_{i}$ are the nodal temperatures (in this case, $j=4$ as linear rectangular elements are considered).

Using the Galerkin method, we can rewrite eq. (11) at the element level in the following form:

$$
\begin{aligned}
\int_{\Omega_{e}} N_{i}^{e}\left\{\left[\frac{\partial}{\partial x}\left(k_{x} \frac{\partial}{\partial x}\right)\right.\right. & \left.+\frac{\partial}{\partial y}\left(k_{y} \frac{\partial}{\partial y}\right)\right] N_{j}^{e} T_{j}^{e} \\
& \left.+\rho H \frac{d \alpha}{d t}-\rho C \frac{\partial}{\partial t} N_{j}^{e} T_{j}^{e}\right\} d \Omega=0
\end{aligned}
$$

Applying Gauss's theorem to the equation and after insertion of boundary conditions, we arrive to the following relation:

$$
\begin{aligned}
-\int_{\Omega e}\left(\frac{\partial N_{i}^{e}}{\partial x} k_{x} \frac{\partial N_{j}^{e}}{\partial x}+\frac{\partial N_{i}^{e}}{\partial y} k_{y} \frac{\partial N_{j}^{e}}{\partial y}\right) T_{j}^{e} d x d y \\
+\int_{\Omega e} N_{i}^{e} \rho H \frac{d \alpha}{d t} d x d y-\int_{\Omega e} N_{i}^{e} \rho C N_{j} \dot{T}_{j}^{e} d x d y \\
\quad+\oint_{\Gamma e} N_{i}^{e}\left[I-h\left(N_{j}^{e} T_{j}^{e}-T_{\infty}\right)\right] d \Gamma=0
\end{aligned}
$$

where the dot denotes the time differentiation. After some manipulations, eq. (25) becomes:

$$
\begin{array}{r}
\int_{\Omega e} N_{i}^{e} \rho C N_{j}^{e} \dot{T}_{j}^{e} d x d y+\int_{\Omega e}\left(\frac{\partial N_{i}^{e}}{\partial x} k_{x} \frac{\partial N_{j}^{e}}{\partial x}+\frac{\partial N_{i}^{e}}{\partial y} k_{y} \frac{\partial N_{j}^{e}}{\partial y}\right) \\
\times T_{j}^{e} d x d y+\oint_{\Gamma e} N_{i}^{e} h N_{j}^{e} T_{j}^{e} d \Gamma=\int_{\Omega e} N_{i}^{e} \rho H \frac{d \alpha}{d t} d x d y \\
+\oint_{\Gamma e} N_{i}^{e} I d \Gamma+\oint_{\Gamma e} N_{i}^{e} h T_{\infty} d \Gamma=0
\end{array}
$$

Equation (26) can also be expressed in a matrix form, using the following equation:

$$
C \dot{T}+K T=F
$$

where $C$ is the heat capacity matrix, $K$ is the conductivity matrix, and $F$ is the equivalent nodal heat flow vector. In photofabrication processes, because of the shape of the light beam, a cylindrical coordinate system $(r, \theta, z)$ must be used. For this situation, assuming that the resin is spatially homogeneous, cylindrical symmetry can be assumed. This means that both the geometry and boundary conditions are independent of the angular coordinate $\theta$. This allows light intensities, fractional conversions, rates of gel formation, and temperatures to be functions of the two spatial coordinates $(r, z)$ and time. In these cases, the integration with respect to $\theta$ yields a multiplicative constant $2 \pi$, and the matrix elements in the eq. (27) become: 
TABLE I

The Values for the Gauss Points and Weighting Factors

\begin{tabular}{rrrrr}
\hline$k \times k$ & $\xi_{i}$ & \multicolumn{1}{c}{$\eta_{j}$} & $W_{i}$ & $W_{j}$ \\
\hline $2 \times 2$ & -0.57735 & -0.57735 & 1 & 1 \\
& -0.57735 & 0.57735 & & \\
& 0.57735 & -0.57735 & & \\
& 0.57735 & 0.57735 & & \\
\hline
\end{tabular}

$$
\begin{gathered}
C_{i j}^{e}=2 \pi \int_{\Omega e} N_{i}^{e} \rho C N_{j}^{e} r d r d z \\
K_{i j}^{e}=2 \pi \int_{\Omega e}\left(\frac{\partial N_{i}^{e}}{\partial r} k_{r} \frac{\partial N_{j}^{e}}{\partial r}+\frac{\partial N_{i}^{e}}{\partial z} k z \frac{\partial N_{j}^{e}}{\partial z}\right) r d r d z \\
+2 \pi \oint_{\Gamma e} N_{i}^{e} h N_{j}^{e} r d \Gamma \\
F_{i}^{e}=2 \pi \int_{\Omega e} N_{i}^{e} \rho H \frac{d \alpha}{d t} r d r d z+2 \pi \oint_{\Gamma e} N_{i}^{e} I d \Gamma \\
+2 \pi \oint_{\Gamma e} N_{i}^{e} h T_{\infty} r d \Gamma
\end{gathered}
$$

The two-time-level Cranck-Nicolson algorithm method of unconditional stability was used to integrate eq. (27) with respect to time. ${ }^{32,33}$ According to this algorithm, the unknown values of temperature at time point $t_{n+1}$ are determined by the known temperatures at time point $t_{n}$, considering the following temporal approximation:

$$
\{T\}_{n+1}^{e}=\{T\}_{n}^{e}+\frac{1}{2} \Delta t\left(\{\dot{T}\}_{n+1}^{e}+\{\dot{T}\}_{n}^{e}\right)
$$

which can be applied to the matrix eq. (27) that becomes:

$$
\left(C+\frac{1}{2} \Delta t K\right) T_{n+1}=\left[C-\frac{1}{2} \Delta t K\right] T_{n}+\frac{1}{2} \Delta t\left[F_{n+1}+F_{n}\right]
$$

where the subscript denotes the time at which the corresponding term must be evaluated, and $\Delta t$ is the time step.
Linear rectangular elements were considered and the concept of isoparametric formulation was used. . $^{32,33}$

Numerical integration is used to evaluate eqs. (28)-(30). The Gauss-Legendre quadrature rules were used to perform such a numerical integration. Numerical quadrature formulas in quadrilateral elements have the following form ${ }^{32,33}$ :

$$
\begin{aligned}
\int_{\Omega e} F(\xi, \eta) d \xi d \eta=\int_{-1}^{1} \int_{-1}^{1} F(\xi, \eta) d \xi d \eta \\
\\
\approx \sum_{i=1}^{k} \sum_{j=1}^{k} F\left(\xi_{i}, \eta_{j}\right) W_{i} W_{j}
\end{aligned}
$$

where $W_{i}$ and $W_{j}$ are the weighting gauss factors and $k$ is the number of integration or gauss points. A $2 \times 2$ integration rule for linear rectangular elements is used. The corresponding values for quadrature points and weighting factors are indicated in Table I. ${ }^{34}$

\section{RESULTS AND DISCUSSION}

The photo-thermal-kinetic model is used to predict the necessary time to achieve a complete cure for a layer of UP resin containing different concentrations of photoinitiator, UV irradiated at room temperature. A general-purpose UP resin (CRYSTIC 272 supplied by Scott Badder, Wellingborough, UK) was selected for this research work. The resin is a viscous, clear solution of a very pale yellow color and contained $24 \mathrm{~mol} \%$ isophtalic acid, $22 \mathrm{~mol} \%$ fumaric acid (including a small fraction of maleic anhydride), $29 \mathrm{~mol} \%$ diethylene glycol, and $25 \mathrm{~mol} \%$ propylene glycol as determined by ${ }^{1} \mathrm{H}-\mathrm{NMR}$ and is shown in Figure 4. According to the supplier, the acid value is $18 \mathrm{mg} \mathrm{KOH} / \mathrm{g}$. The number-average molecular weight of the UP resin, $3111 \mathrm{~g} / \mathrm{mol}$, was estimated using the following expression:

$$
\bar{M}_{n}=\frac{\text { molar mass of } \mathrm{KOH}(\mathrm{g} / \mathrm{mol})}{\text { acid value }(\mathrm{mg} \mathrm{KOH} / \mathrm{g})} \times 1000
$$

The styrene content $(\approx 37$ wt $\%)$ was determined by evacuating the styrene monomer in the vacuum

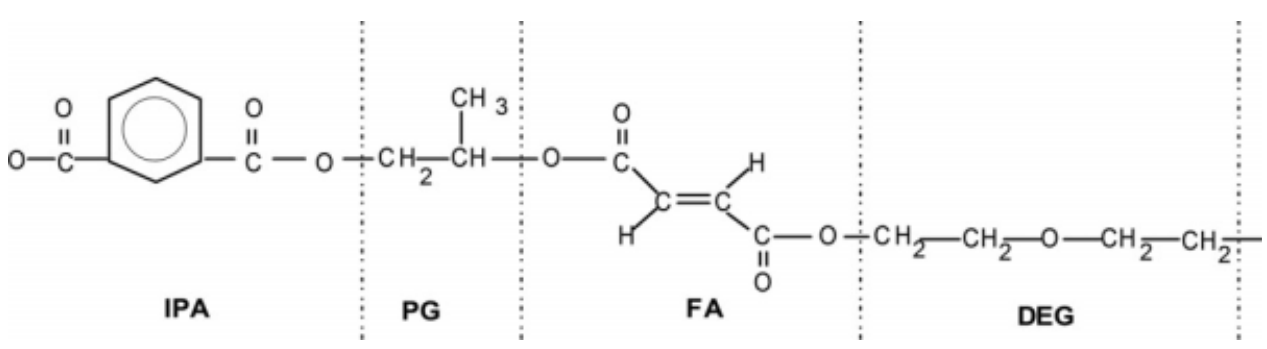

Figure 4 The UP resin structure. 
TABLE II

Composition of the UP Resin Used in This Study

\begin{tabular}{lc}
\hline Composition (mol \%) & \\
Isophthalic acid & 24 \\
fumaric acid & 22 \\
propylene glycol & 25 \\
diethylene glycol & 29 \\
Molar ratio of glycols to dicarboxylic acids & 1.2 \\
Styrene content $(\mathrm{wt} \%)$ & 37 \\
Number-average molecular weight $(\mathrm{g} / \mathrm{mol})$ & 3111 \\
Unit molecular weight $/ \mathrm{mol}$ polyester $\mathrm{C}=\mathrm{C}(\mathrm{g} / \mathrm{mol})$ & 435 \\
Average number of C=C/polyester & 7 \\
Molar ratio of C $=\mathrm{C}$ bonds for styrene-polyester & 2.5 \\
\hline
\end{tabular}

oven at room temperature. The detailed composition of the resin used in this study is given in Table II.

The photoinitiator used was Irgacure 651 (CibaGeigy, Basel, Switzerland), which is the trade name for 2,2-dimethoxy-2-phenyl acetophenone. Its molecular structure is shown in Figure 5(a). This is a low melting white crystalline powder initiator with $\lambda_{\max }$ $\approx 340 \mathrm{~nm}$ as determined by UV-visible spectroscopy (for a concentration of $3.6 \times 10^{-4} \mathrm{~mol} / \mathrm{dm}^{3}$, the corresponding absorbance was 0.233 ), useful for curing UP resins. When exposed to UV radiation, this initiator undergoes a Norrish Type-I photoscission process forming two radicals: benzoyl radicals [Species A] and dimethoxybenzyl radicals [Species B] as shown in Figure 5(b). Besides this photoscission reaction, the dimethoxybenzyl radical also undergoes subsequent fragmentation, generating a methyl radical [Species C] as shown in Figure 5(c). Nevertheless, the benzoyl radical is the major initiating species.

Material parameter values used in these simulations are summarized in Table III. Some of the values were experimentally determined, whereas others were obtained from relevant literature sources. ${ }^{23,31,35}$

The model was first used to predict the necessary time to achieve a complete cure (no diffusion-controlled effects were considered) for a layer UP resin containing $0.2 \mathrm{wt} \%$ of photoinitiator, which was irradiated at room temperature using an UV lamp. A resin layer with $0.9-\mathrm{cm}$ thickness and $0.7-\mathrm{cm}$ length was considered. In addition, the center of the layer and the center of the light beam, which has a Gaussian distribution profile (see Fig. 6), were assumed to be coincident. Consequently, only onehalf of the resin layer was considered for simulation purposes because of the geometry and light distribution symmetry of the problem. For simulation purposes, a mesh of 210 linear rectangular elements was considered (7 element along the radial direction and 30 along the thickness direction), with dimensions of $0.05 \mathrm{~cm} \times 0.03 \mathrm{~cm}$.

Figure 7 shows contour plots of fractional conversion for different exposure times. The fractional

a)
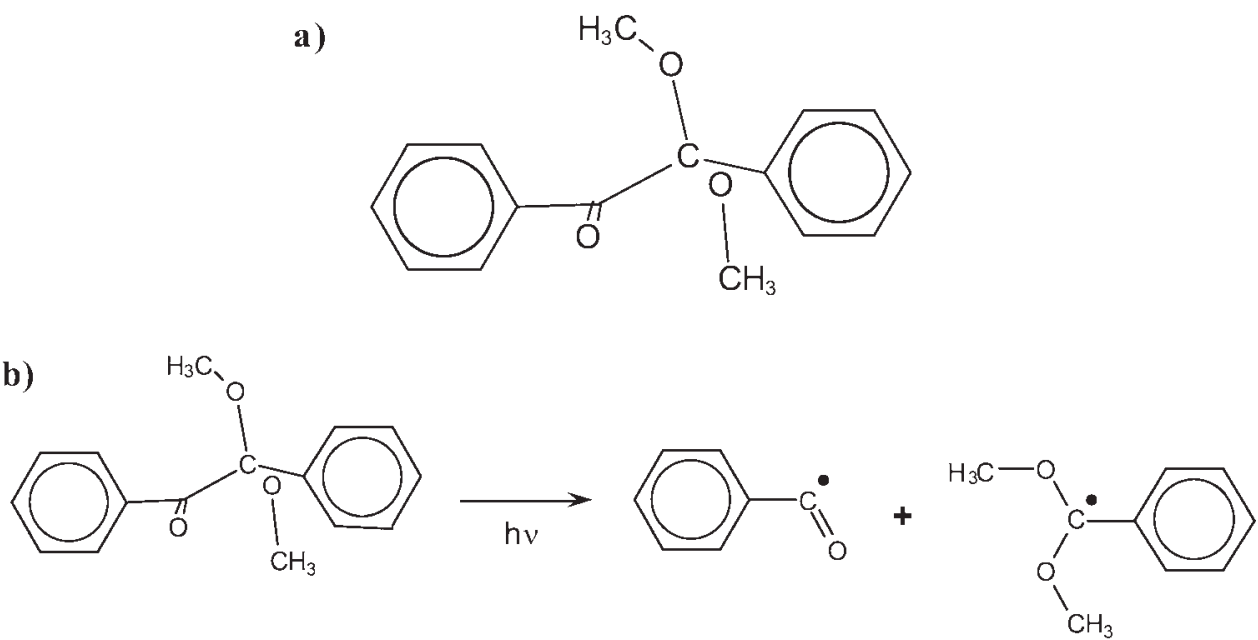

[Species A]

[Species B]

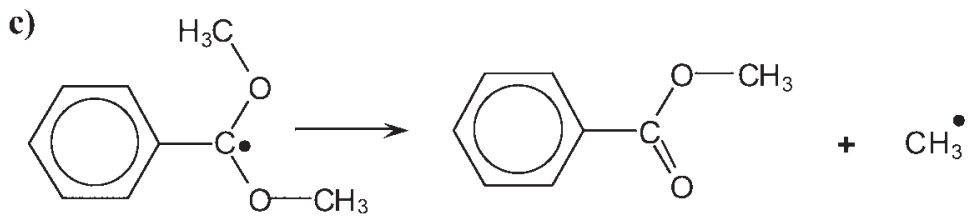

[Species C]

Figure 5 a) Photoinitiator chemical representation; (b) photoscission process of Irgacure 651; and (c) fragmentation process of dimethoxybenzyl radical. 
TABLE III

Material Properties Used in the Simulations

\begin{tabular}{lc}
\hline Property & Value \\
\hline Density & $1.1 \mathrm{~g} / \mathrm{cm}^{3}$ \\
Heat of polymerization & $335 \mathrm{~J} / \mathrm{g}$ \\
Glass transition temperature & $115^{\circ} \mathrm{C}$ \\
$\quad$ of the fully cured polymer & \\
Specific heat & $1.674 \mathrm{~J} /\left(\mathrm{g}{ }^{\circ} \mathrm{C}\right)$ \\
Thermal conductivity & $0.0017 \mathrm{~W} /\left(\mathrm{cm}^{\circ} \mathrm{C}\right)$ \\
Heat transfer & $0.002 \mathrm{~W} /\left(\mathrm{cm}^{\circ}{ }^{\circ} \mathrm{C}\right)$ \\
Heat of reaction & $335 \mathrm{~J} / \mathrm{g}^{-1}$ \\
Absorptivity of photoinitiator & $5(\mathrm{wt} \% \text { of PI cm })^{-1}$ \\
\hline
\end{tabular}

conversion contour indicates a conical variation, which can be an important factor in terms of the quality of the final models. Higher fractional conversions are obtained at the resin surface because of the high light intensity values. For longer exposure times, it is possible to observe an increase of the fractional conversion with depth because of an increase of the energy values supplied to the resin layer. As a consequence of the decrease of light intensity with depth, according to the Beer-Lambert law, it is possible to observe that with both the light intensity and the photoinitiator concentration, considered in this case, it is not possible to solidify all the thickness. Figures 8 and 9 illustrate the effect of both light intensity and photoinitiator concentration on the curing process. The reaction rate increases by increasing both light intensity and initiator concentration as expected. However, the increase of the photoinitiator concentration decreases the light penetration depth.

The photo-thermal-kinetic model was also used to study the effect of the irradiation from two different light sources having both a maximum light intensity of $100 \mathrm{~mW} / \mathrm{cm}^{2}$. The relative position between the two light sources is shown in Figure 10. The conversion profile is indicated in Figure 11. As in the previ-

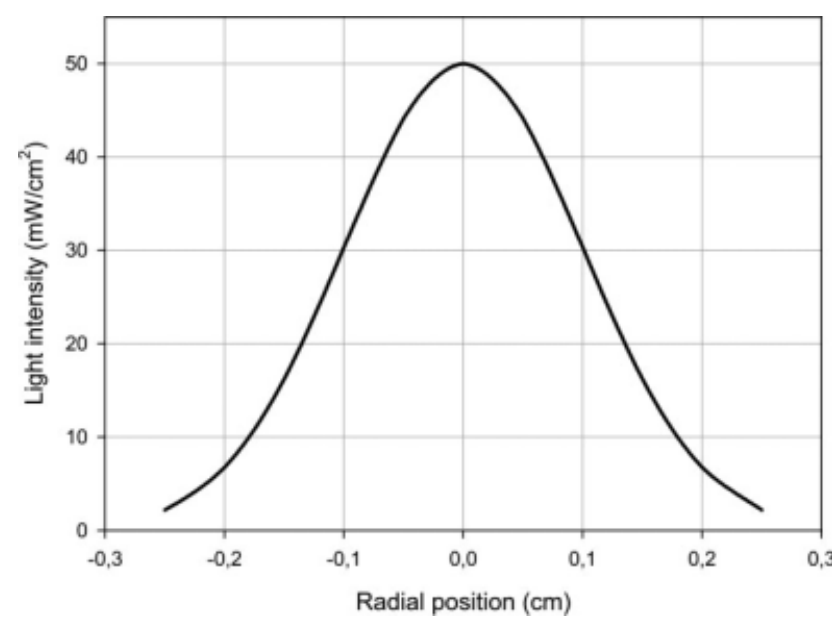

Figure 6 Light intensity profile at the resins' surface. ous case, results show a parabolic profile for the curing process and, in this particular case, a symmetry due to the two irradiation sources (w-like profile of fractional conversion). Maximum values of fractional conversion are also observed at the center of each irradiation profile. The $\mathrm{w}$-like profile of fractional conversion for two light sources can be increased by increasing the difference of maximum light intensities between the two irradiation profiles (Fig. 12) or reduced by reducing the distance
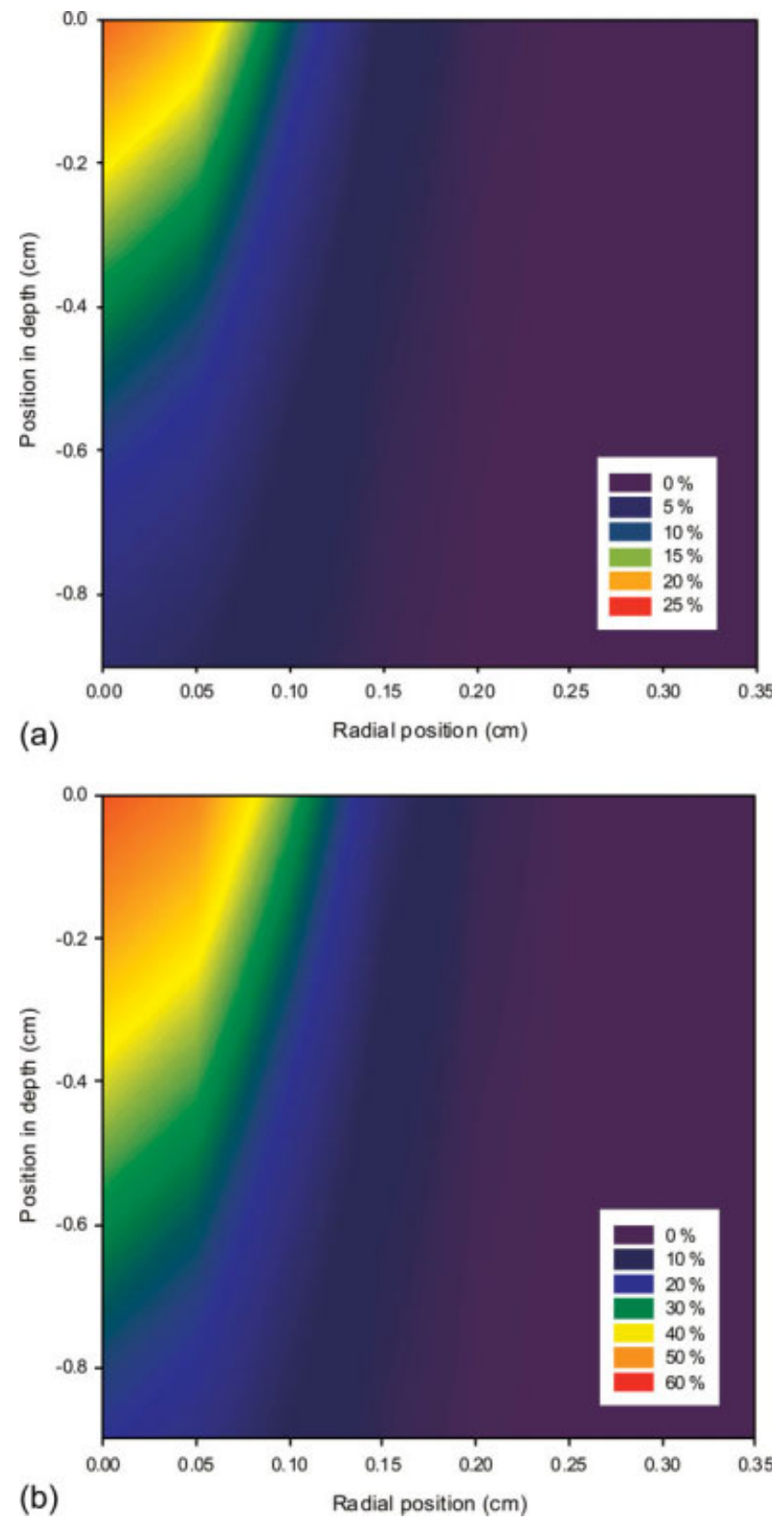

Figure 7 Contour plot showing the variation of fractional conversion as a function of position. Irradiation times: (a) 10 and (b) $15 \mathrm{~min}$. Light intensity: $50 \mathrm{~mW} / \mathrm{cm}^{2}$ of intensity. UP sample containing 0.2 wt \% of photoinitiator. [Color figure can be viewed in the online issue, which is available at www.interscience.wiley.com.] 


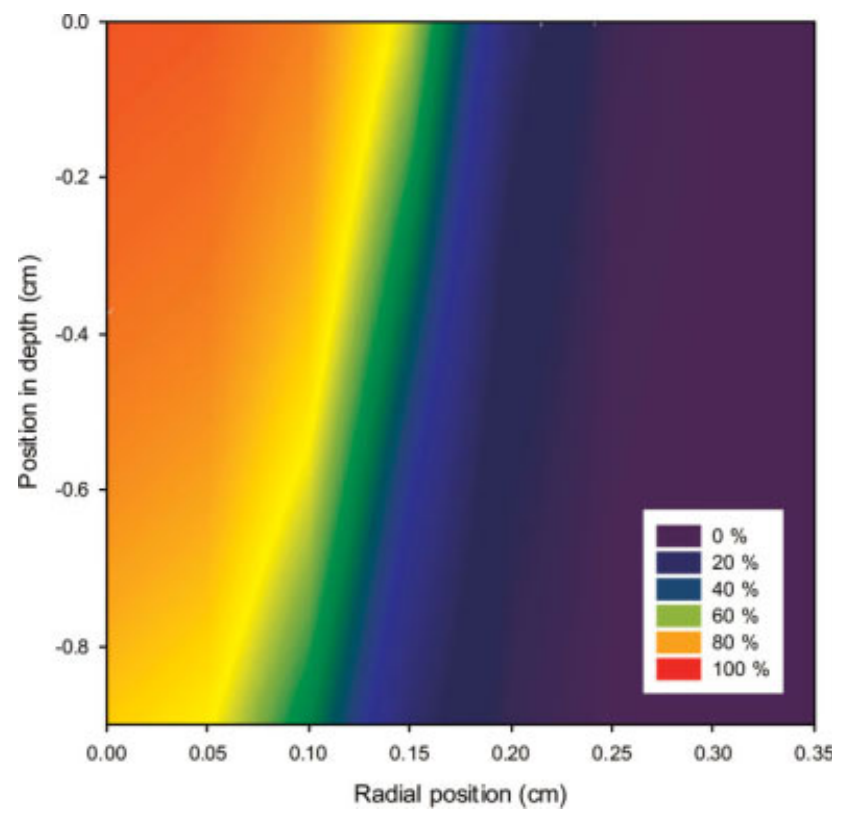

Figure 8 Contour plot showing the variation of fractional conversion as a function of position. Irradiation time: 10 min. Light intensity: $100 \mathrm{~mW} / \mathrm{cm}^{2}$ of intensity. UP sample containing $0.2 \mathrm{wt} \%$ of photoinitiator. [Color figure can be viewed in the online issue, which is available at www. interscience.wiley.com.]

between the centers of each irradiation profile (Fig. 13).

The photo-thermal-kinetic was also used to simulate and study the photomask processes. In this case, a squared mask, a noncollimated light source, and diffusion-controlled curing reactions were considered. The mask is used to define the irradiated area on the surface of a liquid resin layer of $0.03 \mathrm{~cm}$ thickness and $2 \mathrm{~cm}$ length. Similar to the previous situation analyzed, all the problems are considered to have geometry and light distribution symmetry. Consequently, only one-half of the resin layer was considered for simulation purposes. In addition, a resin containing $0.5 \mathrm{wt} \%$ of photoinitiator was considered. Figure 14 shows the variation of the fractional conversion at the surface of the resin as a function of position for a square mask $(1 \mathrm{~cm}$ length) placed $1 \mathrm{~cm}$ above the resin surface. The light intensity at the center of the irradiated area was considered to be $28.1 \mathrm{~mW} / \mathrm{cm}^{2}$, and the sample was exposed to light for $10 \mathrm{~min}$. The simulation was performed considering a nonuniform mesh. The area directly under the mask was modeled using 10 rectangular elements (the dimensions of each element were as follows: horizontal dimension $=0.05 \mathrm{~cm}$ and vertical dimension $=0.03 \mathrm{~cm}$ ). The area immediately after the mask was modeled using 250 elements (the dimensions of each element were as follows: horizontal dimension $=0.002 \mathrm{~cm}$ and vertical dimension $=0.03 \mathrm{~cm}$ ). Finally, to model the rest of the resin layer, 40 rectangular elements were considered (the dimensions of each element were as follows: horizontal dimension $=0.05 \mathrm{~cm}$ and vertical dimension $=0.03 \mathrm{~cm}$ ). Figure 14 shows that due to the light diffracted through the mask, deviations from the ideal dimensions (a square model with 1 $\mathrm{cm}$ length) are produced. To find the optimum conditions to produce exact models, a lateral accuracy index $(\chi)$ was considered. This index, represented in
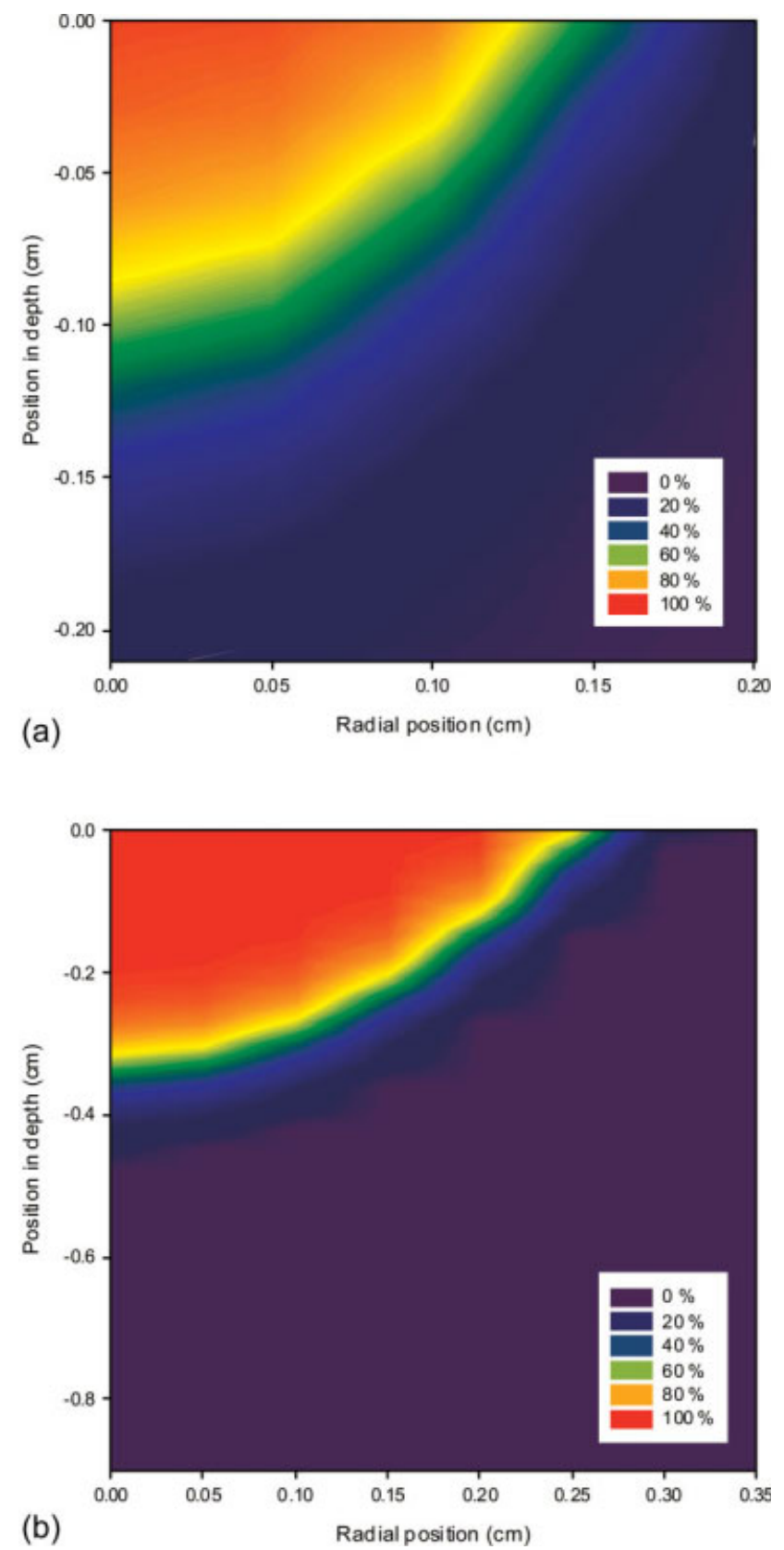

Figure 9 Contour plot showing the variation of fractional conversion as a function of position. Irradiation times: (a) 1 and (b) $5 \mathrm{~min}$. Light intensity: $100 \mathrm{~mW} / \mathrm{cm}^{2}$ of intensity. UP sample containing 2 wt \% of photoinitiator. [Color figure can be viewed in the online issue, which is available at www.interscience.wiley.com.] 


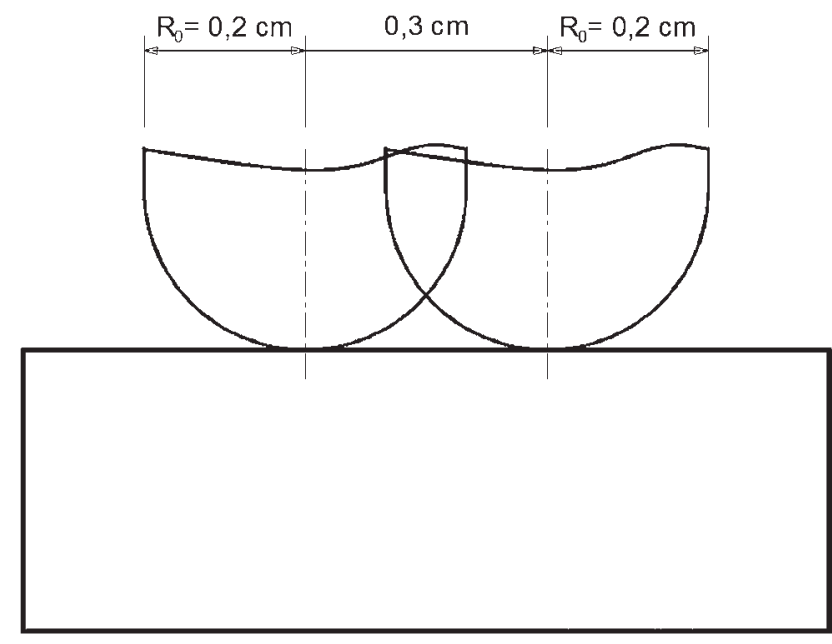

Figure 10 Irradiation through two light sources.

Figure 14, corresponds to the area defined by the fractional conversion versus position line and the boundaries of the exact model. High values of $\chi$ means less resolution, however, when exact models are produced $\chi=0$ at the end of the curing process.

Figure 15 shows the comparison of the variation of fractional conversion and $\chi$ as a function of irradiation time. Fractional conversion values represented in this figure are average values at each position (average of the fractional conversion at the surface and

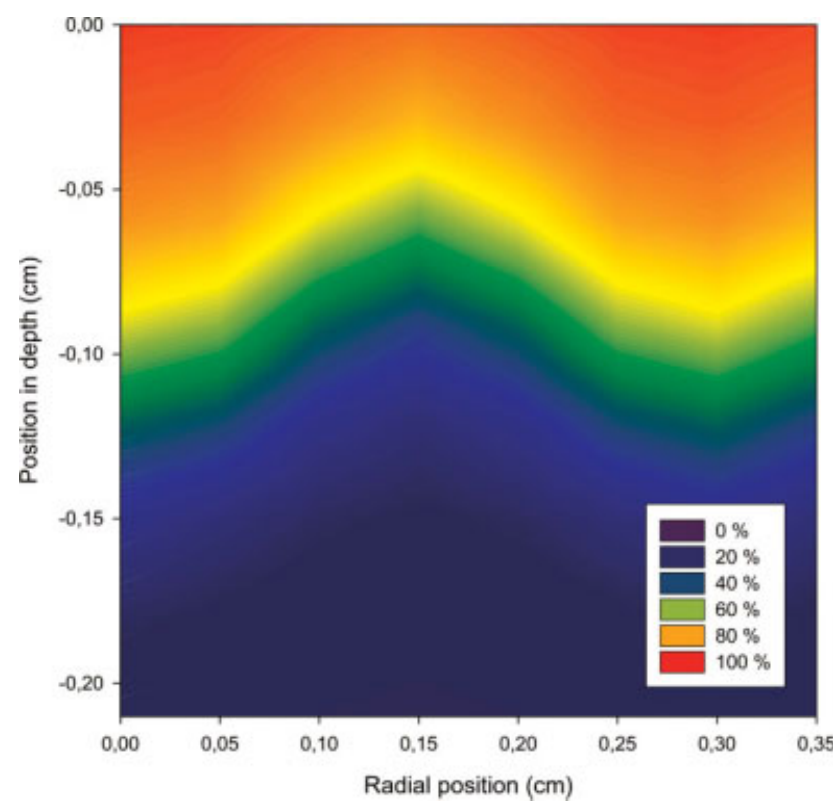

Figure 11 Contour plot showing the variation of fractional conversion as a function of position for an irradiation process using two light beams of same intensity. Irradiation time: $1 \mathrm{~min}$. Maximum light intensity for each light source: $100 \mathrm{~mW} / \mathrm{cm}^{2}$. Distance between the centers of the light beams: $0.30 \mathrm{~cm}$. [Color figure can be viewed in the online issue, which is available at www.interscience. wiley.com.]

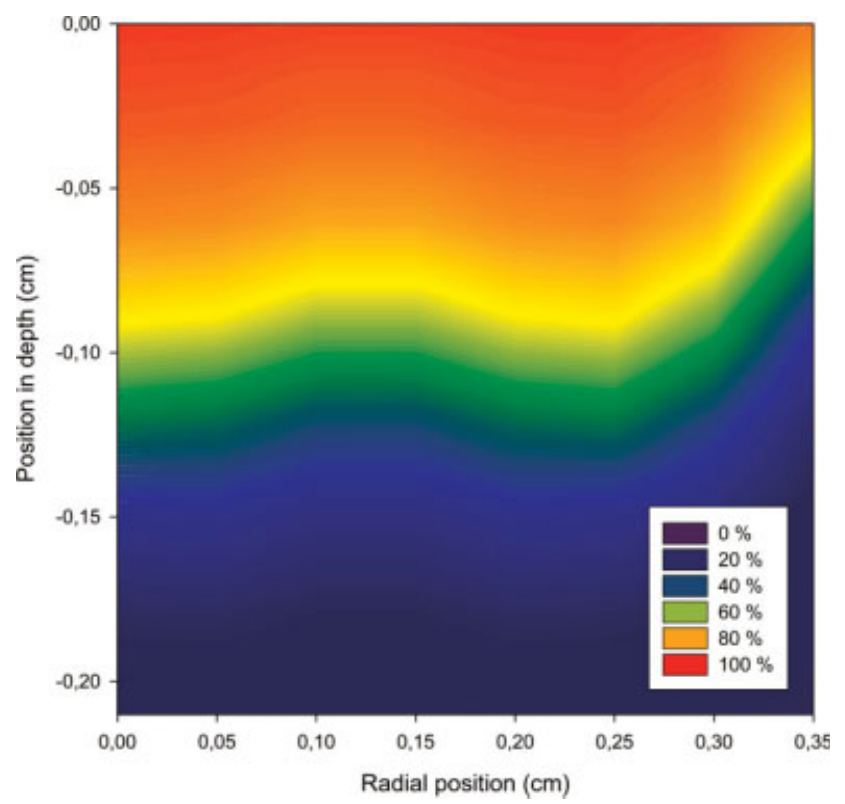

Figure 12 Contour plot showing the variation of fractional conversion as a function of position for an irradiation process using two light beams of same intensity. Irradiation time: $1 \mathrm{~min}$. Maximum light intensity for each light source: $100 \mathrm{~mW} / \mathrm{cm}^{2}$. Distance between the centers of the light beams: $0.25 \mathrm{~cm}$. [Color figure can be viewed in the online issue, which is available at www.interscience. wiley.com.]

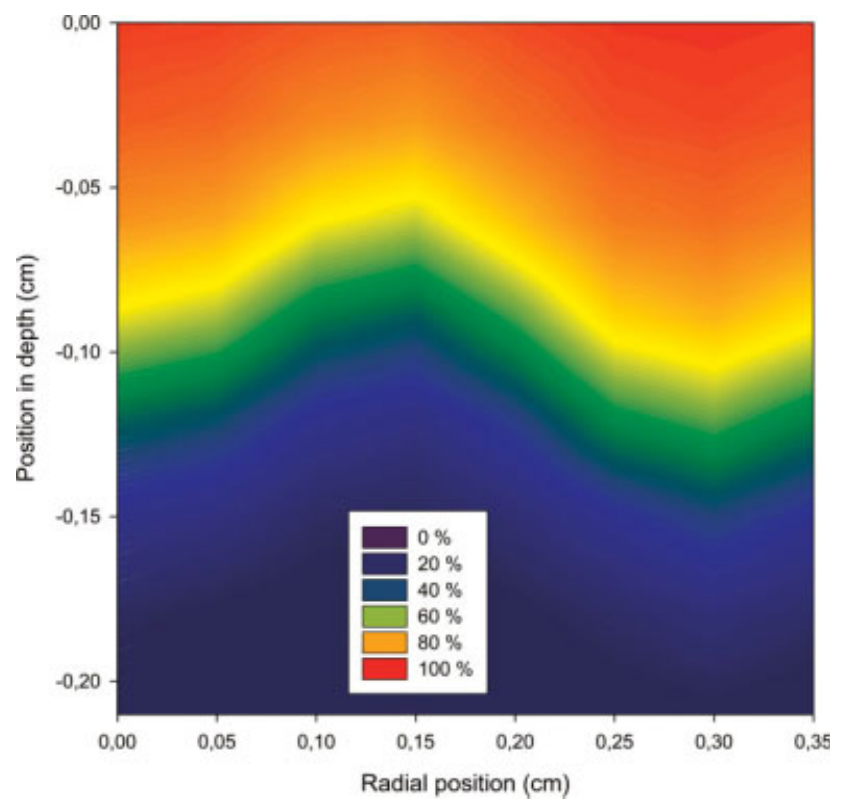

Figure 13 Contour plot showing the variation of fractional conversion as a function of position for an irradiation process using two light beams of different intensities. Irradiation time: $1 \mathrm{~min}$. Maximum light intensity for each light source: $100 \mathrm{~mW} / \mathrm{cm}^{2}$ (left beam) and $120 \mathrm{~mW} / \mathrm{cm}^{2}$ (right beam). Distance between the centers of the light beams: $0.25 \mathrm{~cm}$. [Color figure can be viewed in the online issue, which is available at www.interscience.wiley.com.] 


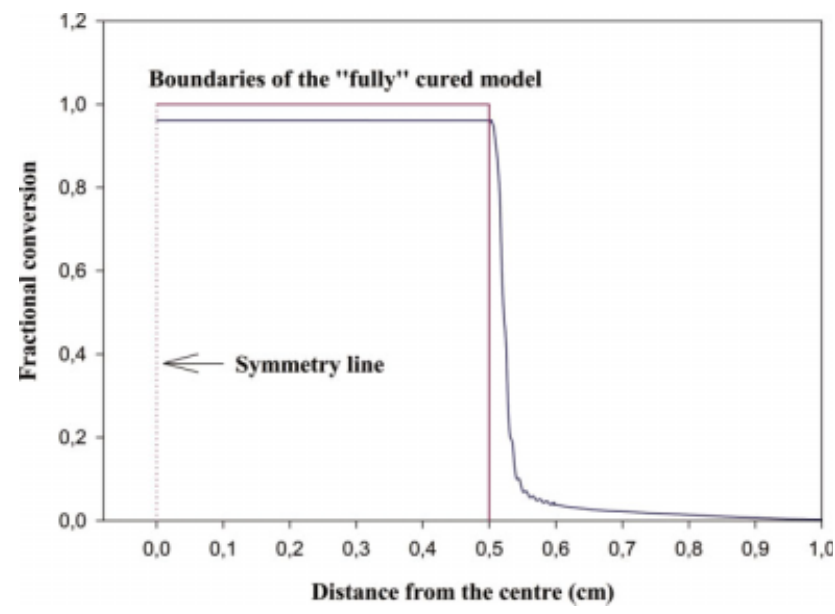

Figure 14 Variation of fractional conversion versus position for a sample irradiated through a squared mask $(1 \mathrm{~cm}$ length) placed $1 \mathrm{~cm}$ above the resins' surface. Irradiation time: $10 \mathrm{~min}$. [Color figure can be viewed in the online issue, which is available at www.interscience.wiley.com.]

bottom of the resin layer for each position). From this figure, it is possible to observe that after vitrification of the resin directly under the mask, continuing exposure to radiation decreases the resolution. In addition, it is possible to verify that initially $\chi$ increases rapidly due to the conversion of the resin inside and outside the area defined by the mask but close enough to receive sufficiently high values of diffracted radiation. After the vitrification of this area, $\chi$ increases more slowly as the major contribution to this index comes from the resin far from the edges of the mask, and consequently, subjected to

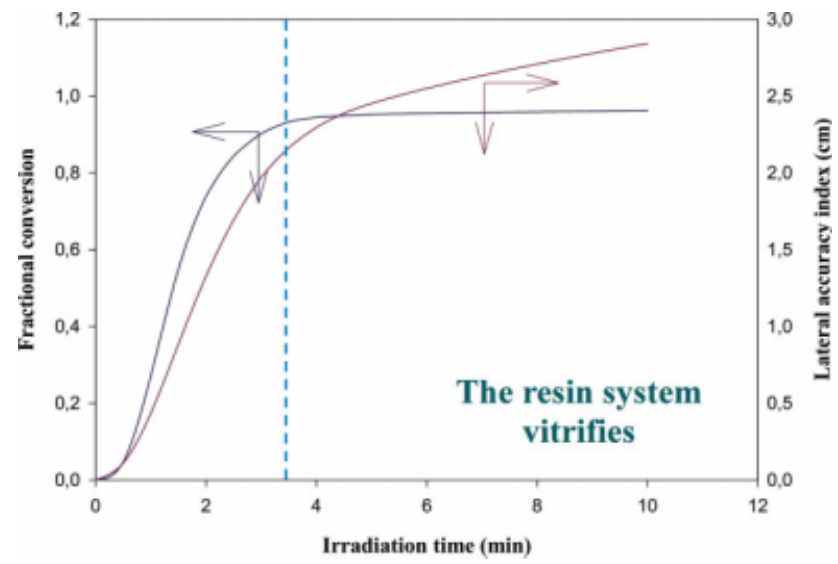

Figure 15 Comparison of the variation of fractional conversion and lateral accuracy indexversus irradiation time. Fractional conversion values are the average values of the fractional conversion at the surface and bottom of the resin layer for each position. Sample irradiated through a squared mask (1 cm length) placed $1 \mathrm{~cm}$ above the resin surface. [Color figure can be viewed in the online issue, which is available at www.interscience.wiley.com.]

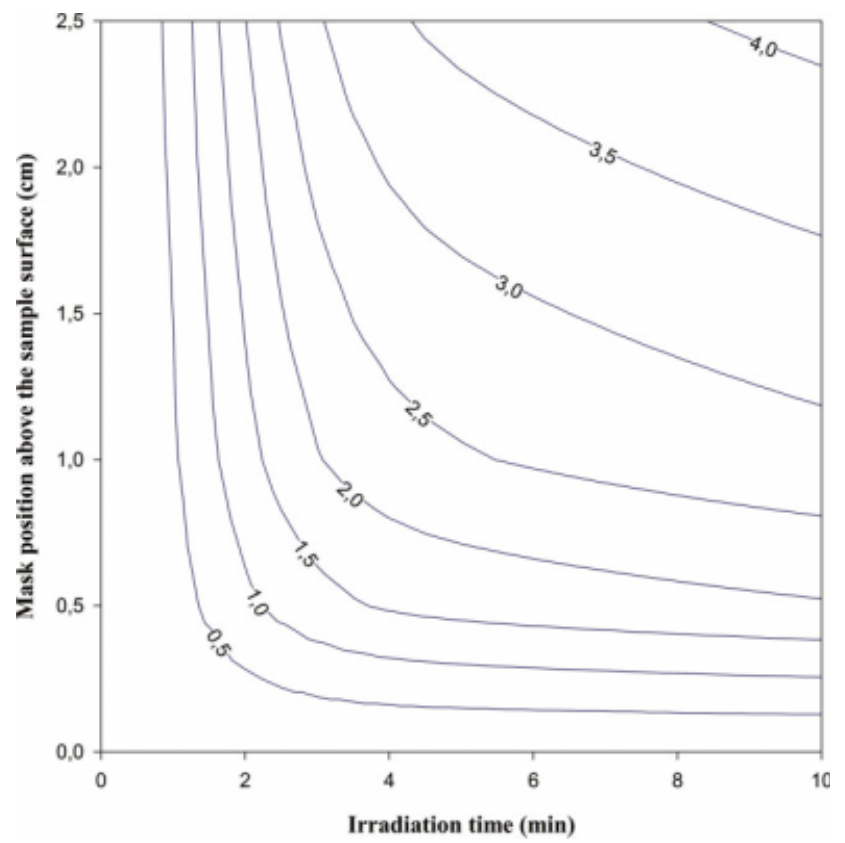

Figure 16 Contour plot showing the variation of $\chi$ as a function of mask position and irradiation time. [Color figure can be viewed in the online issue, which is available at www.interscience.wiley.com.]

low-intensity-diffracted radiation and to slow reaction rates.

The effect of the mask position above the resin surface layer is indicated in Figures 16 and 17,

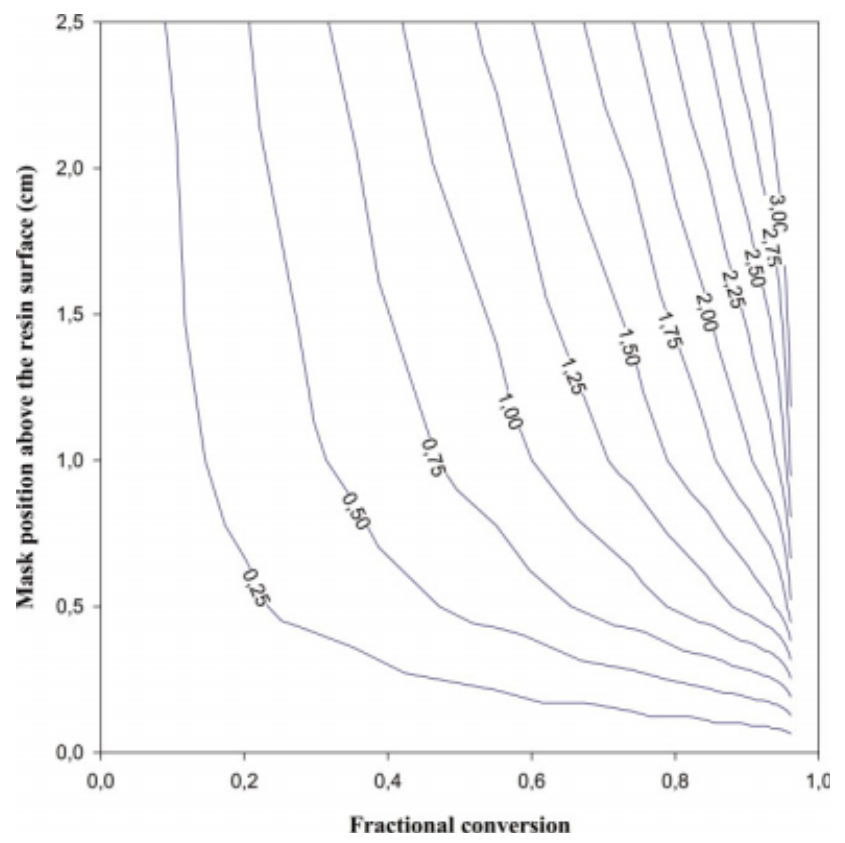

Figure 17 Contour plot showing the variation of $\chi$ as a function of mask position and fractional conversion. Fractional conversion values are the average values of the fractional conversion considering all the nodes directly under the mask. [Color figure can be viewed in the online issue, which is available at www.interscience.wiley.com.] 
which are contour plots showing the variation of $\chi$ as a function of mask position and irradiation time or fractional conversion. Fractional conversion values are the average values of the fractional conversion considering all the nodes directly under the mask (which define the exact model). As indicated in these figures, less resolution is obtained by increasing the distance between mask and resin, because more radiation is diffracted and a larger area of resin is covered by this radiation.

\section{CONCLUSIONS}

Based on the understanding of the fundamental physical and chemical phenomena governing the curing behavior of an UP resin, a photo-thermal-kinetic model was used for simulation purposes. This model assumes a Gaussian intensity distribution of light at the resin surface, the Beer-Lambert law to model the decrease in light intensity with depth, and Fresnel's diffraction theory to evaluate the effect of diffraction. The model has been numerically solved using the finite element technique. The finite element model has been developed by using the Galerkin method for spatial discretization and the Crank-Nicolson method for temporal discretization. Linear rectangular elements have been considered and the concept of isoparametric formulation used.

From the simulations, it is possible to observe the following facts:

- Because of the decrease in light intensity with depth, fractional conversion contours show a conical variation, which could be an important factor in terms of the quality of the obtained models. This effect can be minimized by decreasing the concentration of photoinitiator because more light can be absorbed along the thickness of the resin layer.

- Light intensity increases the rate of gel formation. Consequently, higher values of fractional conversion are obtained and the necessary exposure time is reduced.

- For photomask systems using noncollimated light sources, the accuracy of the obtained models depend on the right balance of factors such as mask position, light intensity, and resin composition.

- Increasing the distance between the mask and the surface of the resin layer decreases the accuracy of the produced models. This is due to the phenomena of light diffraction and to the fact that the diffraction pattern deviate more from the aperture as the distance between mask and resin increases.

\section{References}

1. Selli, E.; Bellobono, I. R. In Radiation Curing in Polymer Science and Technology; Fouassier, J.-P., Rabek, J. F., Eds.; Elsevier: London, 1993, vol. III, p 1.

2. Lee, K. S.; Kim, R. H.; Yang, D. Y.; Park, S. Prog Polym Sci $2008,33,631$.

3. Prime, R. B. In Thermal Characterization of Polymeric Materials; Turi, E. A., Ed.; Academic Press: London, 1997, p 1380.

4. Shibayama, M.; Ozeki, S.; Norisuye, T. Polymer 2005, 46, 2381.

5. Teil, H.; Page, S. A. J Appl Polym Sci 2004, 93, 1774, 143.

6. Bartolo, P. J.; Gaspar, J. CIRP Ann Manuf Technol 2008, 57, 235.

7. Flory, P. J. Principles of Polymer Chemistry; Cornell University Press: Ithaca, 1967.

8. Mounif, E.; Bellenger, V.; Tcharkhtch, A. J Appl Polym Sci 2008, 108, 2908.

9. Assche, G. V.; Swier, S.; Mele, B. V. Thermochim Acta 2002, $388,327$.

10. Lapique, F.; Redford, K. Int J Adhes Adhesives 2002, 22, 337.

11. Liu, S. B.; Liu, J. L.; Yu, T. L. J Appl Polym Sci 1994, 53, 1165.

12. Huang, Y. J.; Fan, J. D.; Lee, L. J. Polym Eng Sci 1990, 30, 684.

13. Yang, Y. S.; Lee, L. J. Polymer 1988, $29,1793$.

14. Yang, Y. S.; Lee, L. J. Polym Process Eng 1988, 5, 327.

15. Martin, J. L. Polym Eng Sci 2007, 47, 62.

16. Kosar, V.; Gomzi, Z.; Antunovic, S. Thermochim Acta 2005, 433,134

17. Horie, K.; Mita, I.; Kambe, H. J Polym Sci Part A-1: Polym Chem 1969, 7, 2561.

18. Lee, L. J. Polym Eng Sci 1981, 21, 483.

19. Cook, W. D.; Delatycki, O. J Macromol Sci Chem 1978, 12, 769.

20. Yang, Y. S.; Lee, L. J.; Lo, S. K. T.; Menardi, P. J. J Appl Polym Sci 1989, 37, 2313.

21. Stevenson, J. F. Polym Eng Sci 1986, $26,746$.

22. Boeng, H. V.Unsaturated Polyesters: Structure and Properties; Elsevier: Amsterdam, 1964.

23. Bártolo, P. J. PhD Thesis, University of Reading, UK, 2001.

24. Muzumdar, S. V.; Lee, L. J. Polym Eng Sci 1991, 31, 1647.

25. Dusek, K. In Developments in Polymerisation; Haward, R. N., Ed.; Applied Science: London, 1982.

26. Yamaguchi, K.; Nakamoto, T. Mem School Eng Nagoya Univ 1998, 50, 1.

27. Yousefi, A.; Lafleur, P. G.; Gauvin, R. Polym Compos 1997, 18, 157.

28. Bártolo, P. J. Int J Adv Manuf Technol 2007, 32, 480.

29. Bártolo, P. J. CIRP Ann Manuf Technol 2006, 55, 221.

30. Kamal, M. R.; Sourour, S. SPE Tech Paper 1973, 18, 187.

31. Gaspar, J. MSc Thesis, University of Minho, Portugal, 2006.

32. Lewis, R. W.; Morgan, K.; Thomas, H. R.; Seetharamu, K. N.The Finite Element Method in Heat Transfer Analysis; Wiley: Chichester, 1996.

33. Reddy, J. N.; Gartling, D. K.The Finite Element Method in Heat Transfer and Fluid Dynamics; CRC Press: Boca Raton, 1996.

34. Reddy, J. N. Introduction to the Finite Elements Method; McGraw-Hill: New York, 1993.

35. Matias, J. MSc Thesis, University of Aveiro, Portugal, 2007. 